\title{
KLF4 Genome: A double edged sword
}

\author{
Deepti Malik, Deepak Kaul \\ Department of Experimental Medicine \& Biotechnology, Postgraduate Institute of Medical Education \& Research, \\ Chandigarh, India
}

Correspondence: Deepak Kaul. Address: Department of Experimental Medicine \& Biotechnology, Postgraduate Institute of Medical Education \& Research, Chandigarh, India. Email: dkaul_24@hotmail.com

Received: December 30, 2014

Accepted: January 27, $2015 \quad$ Online Published: March 26, 2015

DOI : $10.5430 /$ jst.v5n1p49

URL: http://dx.doi.org/10.5430/jst.v5n1p49

\section{Abstract}

Kruppel like factor 4 (KLF4), member of SP1/KLF transcription factor family is characterized by three extremely conserved $\mathrm{C} 2 \mathrm{H} 2$-type zinc-finger motifs at its carboxyl boundary that are crucial for its interaction with target DNA. Participation of KLF4 in the control of proliferation, differentiation and apoptosis are suggestive for KLF4 critical role in tumorigenesis. Depending on the genetic and cellular context, KLF4 gene acts as both oncogene and tumor-suppressor. KLF4 is a significant regulator in reprogramming of somatic cells to pluripotent cells that can give rise to all of the cell types that make up the body. Multiple in vitro and in vivo studies have shown inhibitory role of KLF4 in epithelialmesenchymal transition (EMT) in various cancer types and loss of KLF4 expression during EMT significantly correlates with tumor angiogenesis, metastasis and aggressiveness. The manuscript updates the interrelationship that exists between epigenomic regulation of KLF4, its effector genes and oncogenic transformation.

\section{Key words}

Tumorigenesis, Genome, Kruppel like factor 4, Oncogene

\section{KLF Genome: Evolution and nature}

Given the pivotal role played by Kruppel like factors (KLFs) in abroad spectrum of physiological and pathological processes, it is not surprising that these transcription factors have acquired great recognition all across the globe. Recent evidence have shown the involvement of KLFs in various processes including cell proliferation, differentiation, apoptosis, metabolism, inflammation, embryogenesis and tumorigenesis. Somatic cells can be re-programmed into pluripotent stem (iPS) and maintenance of embryonic stem cells pluripotent state is reliant on KLFs ${ }^{[1]}$. The three highly conserved cysteine and histidine (C2H2)-type zinc finger motifs at the carboxyl-terminus in KLF chain member's exhibits shared ancestry to the Drosophila melanogaster Kruppel protein, accounting for the name. Although C-terminal region shares similarity, the amino-terminal region of KLFs family members vary significantly that allows them to bind to different coactivators, corepressors and modifiers ${ }^{[2]}$. Till now 17 members have been identified in Kruppel like factor family which are named from KLF1 to KLF17 ${ }^{[3]}$ (see Figure 1). In recent time researchers have discovered a new variant of KLF gene/pseudogene christened as KLF18 which is widely suspected to be present in maximum number of placental mammals with sequenced genomes. KLF18 is chromosomally similar to KLF17 and is suspected to be a result of its duplication ${ }^{[4]}$. The KLF family members are divided into 3 clusters on the basis of functional characteristics. Cluster 1 comprises of KLFs 3, 8 and 12; Cluster 2 family members include KLFs 1,2,4,5,6 and 7 and Cluster 3 includes KLFs 9,10,11,13,14 and 16. Cluster 2 KLF 
family members function as transcriptional activators that have acetyltransferase activity while KLFs in cluster 1 and 3 assist as transcriptional repressors with the help of their interaction with the corepressors mainly carboxy-terminal binding protein (CtBP) and Sin3A respectively. CtBPs represses transcription leveraging histone deacetylases (HDACs) and histone methyltransferases to transcriptional complexes. Deacetylate and methylate histones, result in chromatin compaction and promote gene silencing. Therefore, the common mechanism by which Kruppel like factors regulates transcription is via leveraging chromatin modifiers, cofactors and transcription machinery to the promoters of specific genes ${ }^{[3]}$. Worldwide focus of scientific community on KLF's proteins is sure to throw more light on its additional functions and the role that they play in varied diseases. This review summarizes the role of KLF4 protein and provides details of its physiological functions and their pathophysiological roles.

Figure 1. Representation of similar and dissimilar features of KLF transcription factor family members. The C-terminal region contains three highly conserved zinc finger domains in all KLF members, represented by black rectangles. N-terminal region is different in all members.

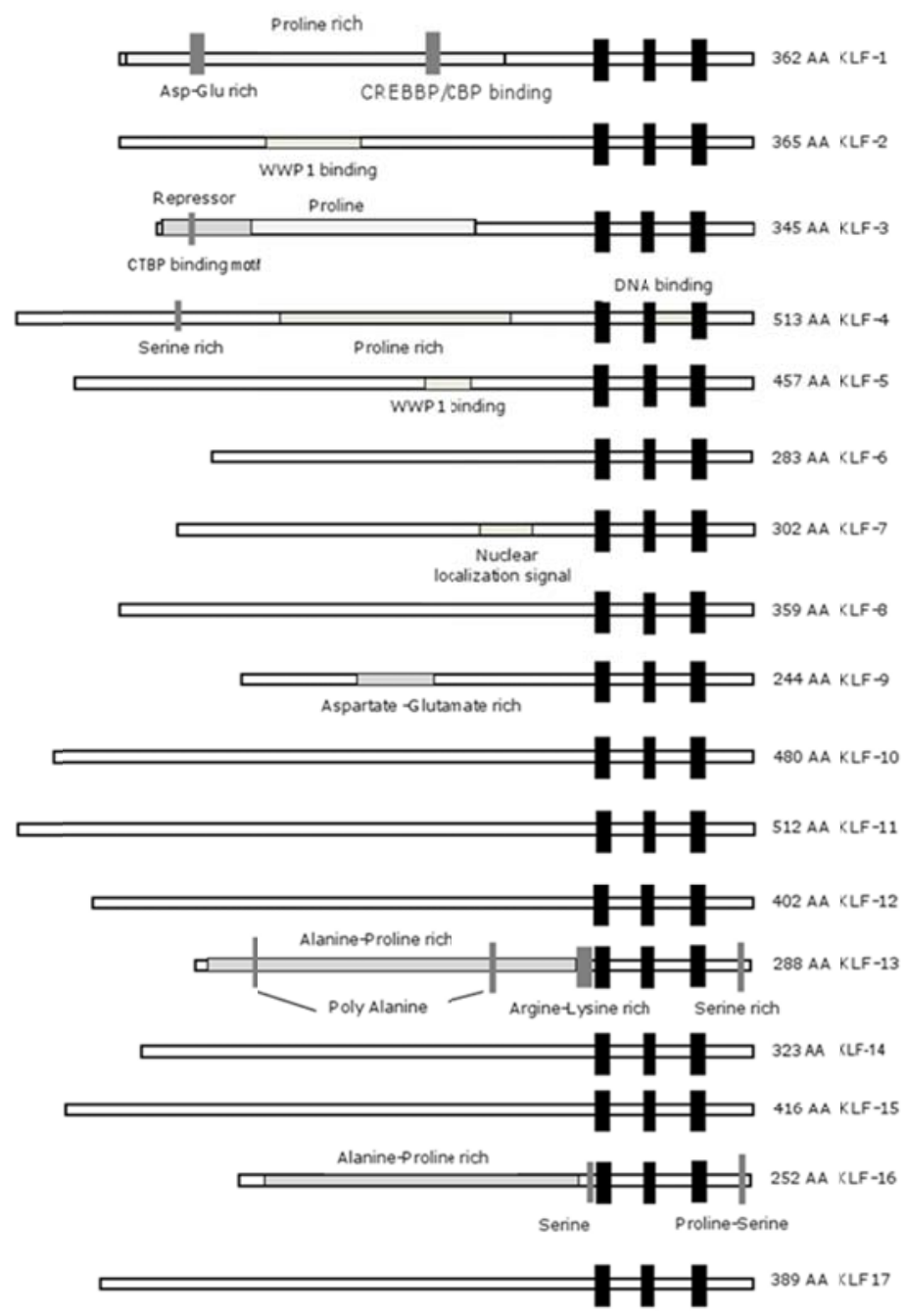

\section{KLF4 epigenomics and its regulation}

Initial cloning of KLF4 was done by two different groups with each group giving it a different name. One group names it as Kruppel like factor (GKLF) due to its high expression in intestine ${ }^{[5]}$ and the other group named it as epithelial zinc finger (EZF) based on the high expression in skin epithelium ${ }^{[6]}$. Subsequently GKLF/EZF was named as KLF4 so as to circumvent misperception as expression of KLF4 is also evident in the lung, skin, testis ${ }^{[5,6]}$, thymus ${ }^{[7]}$, cornea ${ }^{[8]}$, cardiac myocytes ${ }^{[9]}$ and lymphocytes ${ }^{[10]}$. Furthermore KLF4 is imperative in growth as it is measurable in the mouse embryo, with the peak of expression in advanced stages. The human KLF4 gene locus is mapped on chromosome 9q31. Human 
KLF4 has an ORF of $1444 \mathrm{bp}$ coding for a 470 amino acid protein with an estimated molecular mass of $52 \mathrm{kDa}$. The transcription factor KLF4 contains three functional domains, an acidic N-terminal transactivation domain followed by a repressor domain and a C-terminal DNA mandatory domain ${ }^{[11]}$. The DNA binding domain contains three highly conserved zinc finger motifs which help KLF4 to bind with GC or CACCC-boxes in DNA with diverse affinity. It has two nuclear localization signals (NLS), the first of which is located between repressor and DNA binding domain, and second is placed within first two zinc fingers. KLF4 gene also has PEST sequence, located between activation and repressor domain which allows KLF4 to undergo ubiquitin-mediated proteasomal degradation. Activation and repressor domains provide KLF4 with the capacity to influence target gene transcription in a positive or negative way depending on the cellular context. The following section will shed more light on the importance of KLF4 in cellular genomics.

\subsection{KLF4 and Wnt signaling}

$\beta$-catenin plays a pivotal role in mediating cell-cell adhesion and its involvement in many processes including embryogenesis, differentiation, tumor growth and progression has been well elucidated. In normal cells, accumulation of $\beta$-catenin in the cytoplasm is eluded since a destructive complex consisting of proteins including axin, adenomatous polyposis coli (APC), glycogen synthase kinase $3 \beta$ (GSK-3 $\beta$ ) and casein kinase $1 \alpha$ (CK1 $\alpha)$ degrades $\beta$-catenin by ubiquitination. However, upon reception of the Wnt signal, the destruction complex becomes disrupted leading to maintenance of cytoplasmic $\beta$-catenin levels which then increase in the nucleus, activating target genes such as cyclin-D1 and c-Myc with the help of members from LEF/TCF family of DNA binding proteins ${ }^{[12]}$. Inappropriate expression of these genes would result in massive proliferation leading to malignant transformation. A high level of $\beta$-catenin activity is directly related to the severity of cancer invasiveness and progression ${ }^{[13,14]}$. Numerous belligerent and mortal diseases like gastric, lung and breast cancers are characterized by increased $\beta$-catenin expression which weakens cell-cell junctions and promote carcinoma cell dedifferentiation, hyper-proliferation, invasion and metastasis ${ }^{[12]}$. KLF4 is an opponent of $\beta$-catenin and studies have reported possible association between the two in a variety of cancer types ${ }^{[15]}$. Investigation of expression levels of these genes revealed significant increased expression of $\beta$-catenin and down-regulated expression of KLF4 in colon neoplasm ${ }^{[16]}$. In colorectal carcinogenesis, decreased expression of KLF4 reduces its ability to inhibit $\beta$-catenin expression levels ${ }^{[16]}$. An inverse association of their expression levels has been reported in gastric cancer; loss of KLF4 expression is correlated with increase $\beta$-catenin levels ${ }^{[17]}$. A similar behavior was reported in lung (A549), colon (SW480), and breast (T47D) cancer cell lines ${ }^{[18]}$. Forced increased expression of KLF4 inhibits invasion and metastasis of gastric cancer by down-regulating $\beta$-catenin expression and subsequently repressing $\beta$-catenin mediated gene expre ssion ${ }^{[19]}$. Various studies have shown different mechanisms of $\beta$-catenin regulation by KLF4 in cancer types. Some studies reported that KLF4 controls $\beta$-catenin by directly binding and inhibiting its transcriptional activation domain while some other studies have shown KLF4 prohibiting the binding between $\beta$-catenin and p300/CBP ${ }^{[15,16]}$. KLF4 and p300/CBP compete with each other to bind the C-terminus region of $\beta$-catenin and KLF4 may block p300/CBP-mediated acetylation of $\beta$-catenin thus inhibiting histone acetylation on c-Myc and survivin genes. Down-regulation of $\beta$-catenin resulted in clamp down of the Wnt signaling pathway providing anti-tumorigenic and anti-proliferative properties on the cells.

\subsection{KLF4 and notch signaling}

The Notch signaling pathway is activated in gliomas, lung cancer, breast carcinomas, liver cancer, T-cell leukemia/ lymphoma, acute promyelocytic leukemia ${ }^{[18]}$. Notch signaling influences multiple pathways that are involved in cell survival, cell growth, cell proliferation, apoptosis and thus aberrant expression of Notch is linked with tumor progression in a variety of cancer types. Supporting evidence suggests both oncogenic and tumor suppressive role of Notch in various cancers depending on genetic and cellular context. In T-cell acute lymphoblastic leukemia, Notch signals activate PI3K-AKT-mTOR signaling, significantly up-regulate expression of oncogene c-Myc and increase NFkB expression through activation of IkB kinase triggering cell growth (see Figure 2). Constitutive activation of PI3K-AKT signal transduction pathway triggers signals responsible for mediating multiple cellular responses including increased cell growth, cell proliferation, cell survival and cell death ${ }^{[20]}$. Crosstalk's between Notch and KLF4 has been reported extensively, and several studies indicate that Notch signaling inhibits KLF4 expression in intestinal tumors and colorectal 
cancer cells. If Notch Signaling is inhibited it results in increase in KLF4 expression and goblet cell differentiation, resulting in reduction of proliferation and tumor formation ${ }^{[21]}$. In HT29 human colon cancer cells, overexpression of either Notch intracellular domain (NICD)/full-length Notch hinders KLF4 expression and promoter activity with an increase in the rate of proliferation. Moreover, inhibition of Notch signaling by $\gamma$-secretase inhibitor dibenzazepine or siRNA against Notch leads to an increase in KLF4 expression resulting in decreased cellular proliferation ${ }^{[21]}$. Constitutively active version of Notch, ICN1 (a COOH-terminal region of human Notch-1) inhibits KLF4 promoter activity in HCT116 colon cancer cells in vitro ${ }^{[22]}$. KLF4 inhibition by Notch is constant with tumor suppressor role of KLF4 and up regulation of Notch in tumors. Interestingly, in keratinocytes KLF4 binds with Notch1 promoter and in conjunction with Sp3, it functions as a negative regulator of Notch1 gene transcription ${ }^{[23]}$. Also, in murine model, KLF4 is overexpressed exclusively in the endothelium. Persistent KLF4 expression increases ineffective angiogenesis resulting in diminished tumor growth. Sustained EC KLF4 expression in vivo results in extensive alteration to vascular network formation, leading to immense physiological consequences clearly shown by tumor angiogenesis model, consistent with inhibition of the dynamic expression patterns of the DLL4/Notch1 signaling pathway ${ }^{[24]}$.

Figure 2. Constitutive activation of PI3kinase activity in T-cell acute lymphoblastic leukemia as a consequence of engagement of growth factor to its receptors or increased Notch levels activates oncogene AKT which in turn influence many downstream target genes responsible for mediating cellular responses including increased cell growth, cell proliferation, cell survival, cell death and angiogenesis.

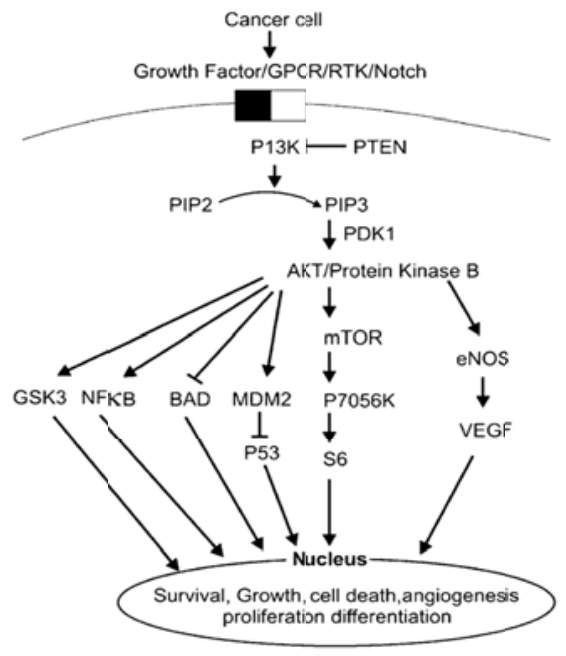

\section{3 miRNA-mediated regulation of KLF4}

The discovery of microRNAs (miRNAs) as the most potent regulators of genomic expression added up a new dimension to our understanding of an oncogenic process. miRNAs are short non-coding RNA sequences, 19-24 nucleotides in length that function both as tumor suppressor and oncogene by modulating the expression of a multitude of genes involved in tumor progression. They are transcribed by RNA polymerase II to form primary miRNA transcripts that are subsequently processed by RNase III enzymes Drosha and Dicer endonucleases. Drosha in collaboration with DGCR8 (Pasha) follows the conversion of pri-miRNA into pre-miRNAs which are approximately 70-90 nucleotides and are subsequently exported to the cytoplasm. Next, the endonuclease Dicer and its binding partner the transactivator RNA-binding protein (TRBP) slices the pre-miRNAs, generating miR duplexes which are incorporated into miRNA associated RNA-induced silencing complex (miRISC). The strand that resists degradation becomes mature miRNA. This mature miRNA strand binds to 3'untranslated region of the target mRNA and modulate gene expression by either targeting mRNA for cleavage or constraining mRNA translation. Over 1872 mature miRNAs have been reported to date to be expressed in humans and approximately $60 \%$ of human genes are regulated by these non-coding RNA sequences. Governance of gene regulation by miRNAs depends mainly on imperfect binding between 5'end of miRNA usually 2-8 nucleotides, the seed region and the matching sequences in the 3' untranslated regions (3' UTR) of its downstream target mRNA. Partial binding of miRNA to targeted mRNA sequences lead to repression of protein translation with subsequent reduction of protein levels of targeted genes ${ }^{[25-27]}$. Alteration in miRNA expression pattern and their respective targets have been documented in various tumors including different types of leukemia e.g. chronic lymphocytic leukemia (CLL) ${ }^{[28]}$, acute myeloid leukemia ${ }^{[29]}$ and $\mathrm{ALL}^{[30]}$ and in solid tumors including lymphomas, colon, lung, breast and pancreatic cancers ${ }^{[31]}$. The reduction or over- 
expression of miRNAs in different cancer types leads to inappropriate expression of their target genes, which functions either as tumor suppressor or oncogene. As a result, aberrant miRNA-target gene expression promote massive proliferation, tissue invasion, angiogenesis, evasion of apoptosis, de-differentiation that ultimately link to transformed phenotype. High expression of miR-29a targets KLF4 and silences its expression in colorectal cancer. Down-regulation of KLF4 in colorectal cancer strongly correlated with increased cell invasion and metastasis ${ }^{[32]}$. In vascular smooth muscle, miR-146a contains antisense binding sites in the 3'UTR of its target gene KLF4, specifying its negative regulation ${ }^{\text {[33] }}$. Recently we reported that apoptosis antagonizing transcription factor (AATF) encodes novel miRNA miR-2909, which regulates genes involved in inflammation, cell cycle, and immune response ${ }^{[34-36]}$. miR-2909-mediated regulation of KLF4 gene expression has been implicated in pediatric B-cell acute lymphoblastic leukemia (ALL) ${ }^{[37]}$ as well as coronary heart disease (CHD) ${ }^{[38]}$. However, miR-2909 fails to regulate KLF4 gene expression in T-cell acute lymphoblastic leukemia as a consequence of mutation in the 3 'UTR region of KLF4 ${ }^{[37]}$. Further, in human embryonic stem cells, miRNA-145mediates KLF4 repression was observed ${ }^{[39]}$. KLF4 was also shown to be regulated by miR-10b in human esophageal cancer cell lines ${ }^{[40]}$. Additionally, miR-130a and 135b targets KLF4 mRNA in M1 AML patient blasts and silencing of KLF4 in turn arrests the maturation of blood cells at an early progenitor stage with subsequent monocytic differentiation ${ }^{[41]}$.

\section{KLF4 and cell decisions}

KLF4 epigenomics has been shown to affect the variety of cell fate decisions:

\subsection{Cellular proliferation}

Innumerable scientific studies have shed light on the role of KLF4 as a regulator of cell proliferation. In vitro studies using cultured cells have shown there is a temporary association between KLF4 expression and conditions that encourage growth arrest, such as DNA damage, serum deprivation and contact inhibition ${ }^{[6]}$. During DNA damage, P53 stabilization induces KLF4 which promotes the activation of cyclin-dependent kinase inhibitor, $\mathrm{p} 21^{\mathrm{WAF} 1 / \mathrm{Cip}}$. The proximal region of the $\mathrm{p} 21^{\mathrm{WAF} 1 / \mathrm{Cip}}$ promoter contains many specific KLF4 binding sites and binding of KLF4 to these sites recruits $\mathrm{p} 53$ to the $\mathrm{p} 21^{\mathrm{WAF} 1 / \mathrm{Cip}}$ promoter which in turn provides $\mathrm{p} 53$ the ability to drive transcription of the $\mathrm{p} 21^{\mathrm{WAF} 1 / \mathrm{Cip}}$ gene ${ }^{[42]}$. The cell cycle inhibitor $\mathrm{p} 21^{\mathrm{WAF} 1 / \mathrm{Cip}}$ induces arrest at G1/S phase and blocks progression of cells to a next phase (see Figure 3). KLF4 overexpression in RKO cells induces $\mathrm{p} 21^{\mathrm{WAF} 1 / \mathrm{Cip}}$, promotes $\mathrm{G} 1 / \mathrm{S}$ arrest and inhibits cell proliferation ${ }^{[43]}$. Consistent findings were reported in mouse embryonic fibroblasts in which overexpression of KLF4 induce $\mathrm{p} 21^{\mathrm{WAF} 1 / \mathrm{Cip}}$ and acts as a suppressor of cell proliferation ${ }^{[6]}$. In vascular muscle cells, KLF4 plays the role of proliferation inhibitor and prompts $\mathrm{p} 21$, $\mathrm{p} 27, \mathrm{p} 53$, and retinoblastoma $(\mathrm{Rb}){ }^{[44]}$. In addition to its effect on activation of p21 ${ }^{\text {WAF1/Cip }}$, KLF4 exerts its role as suppressor of proliferation by suppressing cyclin D1 and cyclin B, which are responsible for promoting progression the G1-S and G2-M limits, respectively ${ }^{[45,46]}$. In HT29 and RKO colon cancer cells, overexpressed KLF4 results in suppression of cyclin D1 ${ }^{[43]}$. Recently, studies have shown that KLF4 plays a part in preventing mRNA expression of ornithine decarboxylase, a biosynthesis regulatory enzyme which encourages cell proliferation and is involved in the advancement of colon cancer ${ }^{[47]}$. In lung cancer patients, KLF4 expression was found to be drastically reduced, and its restoration induced G1 phase arrest in lung cancer cells with negligible apoptosis induction. Restoration of KLF4 expression in lung cancer cells inhibited lung cancer cell growth in vitro and suppressed the growth of tumors derived from lung cancer cell lines in vivo ${ }^{[48]}$. Overexpression of KLF4 induced G1 arrest in both FG cells and BxPC-3 pancreatic cancer cells ${ }^{[49]}$. Consistently, overexpression of KLF4 suppressed cell growth in bladder cancer cell lines ${ }^{[50]}$. Moreover, murine pro-B/pre-B cell lines altered with BCR-ABL or v-Abl expressed low mRNA and protein levels of KLF4 than stimulated splenic B cells. Restoration of KLF4 in these cells induced cell-cycle arrest, indicated by increased percentage of cells in G1 phase and reduces cell number in S phase ${ }^{[51]}$. These findings suggest that KLF4 exert antiproliferative effects in variety of epithelial and other cancers through its capability to create cell cycle checkpoints and impede the progression of cells to the next phase. 


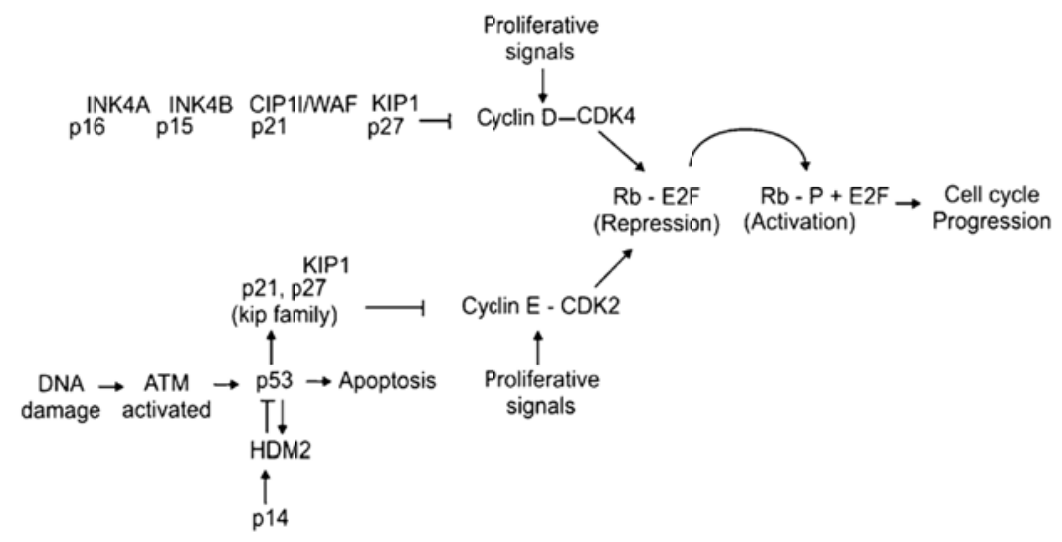

Figure 3. Retinoblastoma $(\mathrm{Rb})$ protein is an essential substrate for cyclin D-associated CDK4 and cyclin E-associated CDK2 kinases. HypophosphorylatedRb, allies with E2F transcription factor and obstructs the natural ability of E2F to transcribe the genes crucial for cell progression to $\mathrm{S}$ phase. Proliferative signals prompted the formation of active cyclinD-CDK4 and cyclinE-CDK2 kinase complexes. These kinase complexes phosphorylate $\mathrm{Rb}$ leading to its dissociation from $\mathrm{E} 2 \mathrm{~F}$ transcription factors resulting in the expression of E2F target genes. The cyclin-dependent kinase inhibitors like $\mathrm{p} 16^{\mathrm{INK} 4 \mathrm{~A}}, \mathrm{p} 15^{\mathrm{INK} 4 \mathrm{~B}}, \mathrm{p} 18^{\mathrm{INK} 4 \mathrm{C}}, \mathrm{p} 21^{\mathrm{CIP} 1 / \mathrm{WAF}}, \mathrm{p} 27^{\mathrm{KIP} 1}$ prevented Rb phosphorylation. HDM2 mediates negative regulation on $\mathrm{p} 53$ expression in normal cells, but DNA damage leads to dissociation between p53 and HDM2 activating p53 that in turn either repair the damage by inducing cell cycle arrest or promote apoptosis under sustained DNA damage.

\subsection{Cellular differentiation}

Studies over a period of time have shed light the role of KLF4 in cell proliferation and/or differentiation. KLF4 plays an active role in transactivation of epithelial genes comprising CYP1A1 ${ }^{[52]}$, laminin $\alpha 3 \mathrm{~A}^{[53]}$, laminin $1^{[54]}$, keratin $4^{[55]}$, keratin $19^{[54]}$. Studies have thrown light on the role of KLF4 in goblet cell differentiation in the intestine ${ }^{[56]}$, and also in the formation of the epithelial fence of the skin ${ }^{[57]}$. Experiments have shown that KLF4-/- mice died in a single day after birth as a result of loss of barrier function of the skin and showed disconcertion of the late-stage variation structure of the epidermis. KLF4 deletion in the colon modifies the terminal differentiation of goblet cells. KLF4-/- mice showed decrease number of mature goblet cells and their number was reduced by $90 \%$ relative to total epithelial cells compared with controls. KLF4-/- mice displayed changed manifestation of the goblet cell marker Muc2 and irregular goblet cell morphology clearly demonstrated by histology and ultrastructural analysis ${ }^{[58]}$. Such kind of cells represents immature pre-goblet cells of goblet cell lineage ${ }^{[57]}$. The mechanism used by KLF4 in regulating goblet cell differentiation is the presence of binding sites for $\mathrm{Cdx} 2$ protein, which control sucrase-isomaltase and lactase markers in intestinal enterocyte differentiation ${ }^{[58,59]}$. Cdx2 plays a positive regulator role in differentiation and a negative role for proliferation making it likely contender for directed KLF4-mediated goblet cell differentiation ${ }^{[59]}$. Remarkably, KLF4 also act as a key transcriptional regulator of monocyte differentiation ${ }^{[60]}$. Overexpressed KLF4 in promyelocytic human HL60 leukemia cells results in monocytic variation and boosted 12-O-tetradecanoylphorbol 13-acetate (TPA) induced macrophage differentiation, but blocked all-trans-retinoic acid RA induced granulocytic differentiation. Sustained expression of KLF4 in primary common myeloid progenitors (CMPs) or hematopoetic stem cells (HSCs) resulted in induction of monocytes differentiation whereas its absence promoted granulocyte differentiation ${ }^{[60]}$. KLF4 plays an enabling role in differentiation of endothelial progenitor cells into endothelial cells ${ }^{[61]}$, odontoblastic differentiation of human dental pulp cells ${ }^{[62]}$, corneal epithelial cell differentiation ${ }^{[63]}$, adipocyte differentiation ${ }^{[64]}$. Conditional removal of KLF4 in the eye causes corneal fragility, edema. Loss of functional KLF4 inhibits adipogenesis and decreased C/EBP $\beta$ levels ${ }^{[64]}$.

\subsection{Cellular apoptosis}

KLF4 affects apoptosis through activation or subjugation of genes involved in cell outcome decisions. Disparate role of KLF4 is responsible for cell destruction in multiple cancer cell lines and tumors acting both as positive and negative regulator of programmed cell death (PCD). KLF4 prompts apoptosis in a range of cancer cells such as lymphoma ${ }^{[51]}$, 
gastric $^{[65]}$, bladder ${ }^{[66]}$ and colon cancer cells ${ }^{[67]}$. KLF4 levels increase significantly in K562 leukemia cells and PBMCs of CML patients in response to $\mathrm{H}_{2} \mathrm{O}_{2}$ stimulation. KLF4 overexpression in K562 cells and PBMC's of CML patients showed increased apoptosis rates for $\mathrm{H}_{2} \mathrm{O}_{2}$ group as compared to control. This increase could be attributed to the activation of caspase 3, up regulation of bax and down regulation of bcl-2. The promoter sequence of bax and bcl-2 contains KLF4 binding site with a strong trans inactivation effect on the bcl-2 promoter and the strong transactivation effect of KLF4 on the bax promoter ${ }^{[68]}$. KLF4 is down-regulated in bladder cancer cell lines and cancer tissues. Transduction of KLF4 using adenoviral vectors induced apoptosis in the same ${ }^{[50]}$. Studies have shown that KLF4 induces apoptosis in murine RAW264.7 macrophages and C2C12 cells ${ }^{[69,70]}$. Amplified expression of KLF4 resulted in apoptosis of N87 and SK-GT5 gastric cancer cells ${ }^{[65]}$ and prostate cancer cell lines PC-3 and DuPro cells ${ }^{[71]}$. KLF4 enforced expression in adult T-cell leukemia cells induces apoptosis ${ }^{[72]}$. In contrast recent publications have supported that KLF4 plays an important role in its ability to inhibit apoptosis in different tumor types. Up-regulated expression of KLF4 suppresses p53 expression inhibiting p53-dependent apoptosis in breast cancer ${ }^{[73]}$. KLF4 represses transcription of p53 in MDA-MB-134 breast cancer cells and inhibits apoptosis. Furthermore, inhibition of KLF4 expression using KLF4-specific siRNA molecules in MDA-MB-134 cells re-establishes p53 levels leading to sudden induction of apoptosis ${ }^{[73]}$. Ectopic expression of KLF4 inhibits apoptosis in TE2 esophageal cancer cell line ${ }^{[74]}$. A newly conducted study has shed light on the fact that KLF4 possibly supersede $\mathrm{Ras}^{\mathrm{V} 12}$-induced senescence in primary fibroblasts, stimulating transformation. Overexpressed KLF4 leads to an increased expression of $\mathrm{p} 21^{\mathrm{Cip} 1 / \mathrm{WAF} 1}$ resulting in cell cycle arrest. Alternatively presence of Ras ${ }^{\mathrm{V} 12}$ leads to inhibition of $\mathrm{p} 21^{\mathrm{Cip} 1 / \mathrm{WAF} 1}$ expression, giving KLF4 the capability to repress $\mathrm{p} 53$ which in turn results in blocked apoptosis and reduced expression of $\mathrm{p} 21^{\mathrm{Cip} 1 / \mathrm{WAF} 1}$, eventually led to transformation +. Thus KLF4 can either act as tumor suppressor or a tumor promoter depending on the genetic and cellular contexts. Exhibiting anti-apoptotic properties in a variety of cancer cells may support KLF4 oncogenic role.

\subsection{Somatic cell reprogramming}

The function of KLF4 has been researched widely with respect to its role in hematopoesis, cell differentiation and tumor formation, but it's role in embryonic stem (ES) cell self-renewal and pluripotency has not got attention that it deserved till recently when spate of studies reported the crucial role of KLF4 in conversion of somatic cells into pluripotent cells. The scientific community still does not properly understand how KLF4 controls ES cell self-renewal and somatic cell reprogramming. Recent cutting edge research has shown that terminally differentiated somatic cells can be reprogrammed to generate induced pluripotent stem (iPS) cells that are similar to ES cells via overexpression of combinations of 4 transcription factors-Oct4, Sox2, c-Myc, KLF4, and Nanog ${ }^{[76,77]}$. c-Myc reactivations is directly responsible for tumor formation and this behavior is crucial safety concern that needs to be addressed before this approach can be used on humans. It is imperative that we develop reprogramming without using c-Myc oncogene. Pluripotent state of fibroblasts can be achieved by Oct4, Sox2, and KLF4 when c-Myc is not present. c-Myc functions as an enhancer of reprogramming and can be removed ${ }^{[78]}$. Oct4 plays a pivotal role in vivo and in vitro for regulation of early embryonic differentiation and maintenance of pluripotency. Presence of even small amounts of Oct4 is essential for thwarting differentiation and supporting ES cell self-renewal ${ }^{[79]}$. Oct4 works in partnership with Sox2, member of the Sox (SRY-related HMG box) gene family for regulating gene expression ${ }^{[80]}$. A key factor in maintaining ES cell pluripotency is Nanog. Nanog's overexpression in ES cells stimulates self-renewal and its deletion prompts the ES cells to undergo differentiation. It is assumed that Nanog functions in conjuction with other factors like Oct4 and Sox2 to establish ES cell identity ${ }^{[81]}$. KLF4 interaction with Oct4 and Sox 2 leads to the formation of complex which binds to Nanog promoter amplifying Nanog's expression which prevents ES cell differentiation. Nanog's expression promotes ES cell pluripotency even when KLF4 manifestation is brought down, however knockdown of Nanog encourages differentiation of ES cells that overexpress KLF4. The above behavior clearly demonstrates that KLF4 functions upstream of Nanog in ES cell self-renewal and in preventing ES cell differentiation ${ }^{[81]}$. KLF4's interactions with c-Myc helps in maintaining iPS cells immortality. KLF4 and c-Myc collaborate to promote iPS cell self-renewal, with KLF4 quashing apoptosis prompted by c-Myc and c-Myc deactivating the cytostatic effect of KLF4 by suppressing p21 ${ }^{[76,77]}$. This creates a balance between KLF4 and c-Myc which may institute the preserved state of iPS cells. KLF4 is highly expressed in undifferentiated ES cells and the expression decreases intensively during differentiation. KLF4 overexpression in ES cells gives it better capacity for 
self-renewal based on secondary embryoid body (EB) formation and its reduced levels in ES cells prompts ES cell differentiation. KLF4's re-expression resulted in relapse of epistem (EpiSCs) cells to pluripotent embryonic stem cell ground state ${ }^{[81,82]}$. The mechanism that may help KLF4 to maintain ES cell renewal is through its upregulated expression by leukemia inhibitory factor (LIF). LIF acts as a catalyst for activation of KLF4 expression, and in this process Oct4 and Sox 2 are also engaged to form a complex with KLF4 that co-localizes on the Nanog promoter which results in the regulation of downstream stemness gene expression in the presence of LIF. LIF removal results in quick decline of KLF4 levels, and as a result Oct4-Sox2 heterodimer binding to Nanog promoter may be impaired leading to Nanog down regulation (see Figure 4). Another explanation can be that KLF4 acts as an enhancer for Oct4 and Sox2 effect on Nanog promoter. When KLF4 is not available even then Oct4 and Sox 2 have the ability to bind with Nanog promoter and control its expression but the effect is not potent and is unable to maintain pluripotency ${ }^{[81]}$. Research results gives credence to the fact that KLF4 acts as a mediator which connects LIF-Stat3 with Nanog resulting in regulation of ES cell self-renewal and pluripotency. KLF4 plays a role in activating Lefty1 promoter, which in turn regulates ES cell identity.


Figure 4. KLF4 interaction with Oct4 and Sox $2 \mathrm{n}$ the presence of LIF leads to the formation of complex which binds to Nanog promoter amplifying Nanog's expression which prevents ES cell differentiation. Decline of KLF4 levels as a consequence of LIF removal resulted in decrease of Nanog expression and thus is unable to maintain pluripotency.

Somatic cell pluripotency generated by ectopic expression of these 4 transcription factors has opened up new avenues in stem cell research. iPS cells mimic ES cells and this presents the scientific community worldwide with exhilarating options in stem cell research and regenerative medicine ${ }^{[76,77]}$. iPS cells can also be used for analyzing pathogenesis of human diseases, for drug discovery and toxicity screening. Somatic reprogramming shows tremendous potential in its ability to generate patient specific pluripotent stem cells, providing a source of autologous cell types which can be used for transplantation therapy. The only hindrance to be overcome is the use of virally transduced transcription factors and proto-oncogenes.

\section{KLF4 and oncogenic transformation}

Dependent on genetic or cellular context KLF4 is known to be expressed as oncogene or tumor suppressor. KLF4 plays a role of a tumor suppressor in variety of cancer types as loss of its expression have contributed significantly to tumorigenesis. Evidence has shown that in pancreatic ductal carcinoma ${ }^{[83]}$, gastrointestinal cancers ${ }^{[65]}$, lung cancer ${ }^{[48]}$, and medulloblastoma KLF4 expression often downregulated ${ }^{[84]}$. In cervical carcinogenesis expression of KLF4 is silenced because of promoter hypermethylation ${ }^{[85]}$. KLF4 is also shown to be inactivated by methylation in adult T-cell leukemia ${ }^{[72]}$. KLF4 expression is known to be low in colorectal cancer ${ }^{[50]}$, bladder cancer ${ }^{[66]}$, gastric cancer ${ }^{[49,65]}$, esophageal squamous cell carcinoma ${ }^{[74]}$, intestinal cancer ${ }^{[21]}$, prostate cancer ${ }^{[18]}$, pediatric B-cell acute lymphoblastic leukemia ${ }^{[37]}$, main cases of B-cell lymphoma, "follicular lymphoma”, diffuse large B-cell lymphoma, Burkitt's lymphoma and in classic Hodgkin's lymphoma, Non-Hodgkin lymphoma ${ }^{[86]}$. KLF4 is also known to have capability to curb ABL-induced transformation of pre-B cells by signifying a tumor suppressor function in some B-cell malignancies ${ }^{[51]}$. KLF4 gene plays a critical role in regulating B-cell maturation, antibody responses and maintenance of B-cell quiescence. 
KLF4 is down-regulated by B-cell activation and remarkable, the inhibition of B-cell propagation by FOXO transcription factors is strongly correlated with KLF4 induction ${ }^{[87,88]}$. Decreased expression of KLF4 is reported in intestinal adenomas, colonic adenomas, and colonic adenocarcinomas of mice and patients with inherited and irregular tumors ${ }^{[2]}$. In comparison to normal tissues it has been found that the levels of KLF4 mRNA are extensively reduced in intestinal adenomas in the APCMin/+ mice and familial adenomatous polyposis (FAP) patients. KLF4 mRNA levels have been found to be significantly repressed in mice infected with intestinal adenomas of multiple intestinal neoplasias (APCMin/ + ). The same behavior is noticed in human patients afflicted with colonic adenomas (FAP) vis a vis adjacent normal mucosa ${ }^{[89]}$. Colon cancer cell lines showed low expression of KLF4 as compared to untransformed colonic epithelial cell line with the lowest mRNA expression was observed in RKO colon cell line ${ }^{[50]}$. In addition loss of heterozygosity (LOH) has been reported in the KLF4 locus in a subset of colorectal cancer specimens ${ }^{[50]}$. Consistent observations of low KLF4 expression was reported in prostate cancer cell lines compared with nontumorigenic prostate cells ${ }^{[18]}$. KLF4 acts as cell cycle regulator and functions as a tumor suppressor through its ability to induce p21 ${ }^{[73]}$ and suppress SP1 expression ${ }^{[90]}$. It competes with SP1 binding site on the Sp1 promoter and negatively regulates the expression of Sp1 transcription factor. Typical overlapping sites for both KLF4 and Sp1 are present on the Sp1 promoter and for which both transcription factors compete for binding; KLF4 negatively regulated Sp1 promoter activity and in contrast Sp1 positively controlled it ${ }^{[00]}$. Thus a loss of KLF4 expression because of epigenetic changes in various tumors may activate high Sp1 expression ${ }^{[90]}$. Overexpression of $\mathrm{Sp} 1$ and reduced expression of KLF4 has been reported in a majority of human gastric cancers ${ }^{[90,91]}$, colorectal cancer ${ }^{[50]}$ and pediatric acute lymphoblastic leukemia ${ }^{[37]}$. High Sp1 expression was directly correlated with an increased metastatic potential, poor prognosis, lymph node metastasis, and low survival in gastric cancer ${ }^{[91]}$, pancreatic

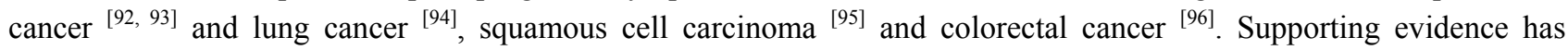
suggested that Sp1 regulates expression of angiogenic genes VEGFR1, VEGFR2, VEGF ${ }^{[97]}$ and growth inhibitory genes such as p21 and caveolin. Its overexpression promotes tumor growth and development and its reduced expression retards tumor growth and angiogenesis in animal models ${ }^{[98]}$. Previous findings from our laboratory reported that increased Sp1 expression up-regulated oncogenes including apoptosis-antagonizing transcription factor (AATF) and c-Myc gene in Jurkat cells ${ }^{[99]}$. High Sp1 expression also led to an increased expression of AATF, c-Myc and BCL3 in pediatric acute lymphoblastic leukemia potentially leading to unbridled transformation ${ }^{[37]}$. The ability of KLF4 to down-regulate Sp1 expression may possibly repress many genes central to the processes of cell growth, angiogenesis and cell invasion and decrease resistance to apoptosis, which may mitigate tumor progression and survival. KLF4 represses several genes involved in angiogenesis, including VEGF-A and endothelin- ${ }^{[100]}$. Low expression of KLF4 in breast cancer cells was correlated with increased VEGF expression. Moreover, co-transfection of these cells with KLF4 and HDAC expression plasmids resulted in suppression of VEGF expression and inhibition of angiogenesis ${ }^{[101]}$. The human VEGF promoter contains overlapping sites for SAF-1 and KLF-4, where SAF-1 induces and KLF-4 suppresses VEGF expression. Low expression of KLF4 in breast cancer cells may lose its competition with SAF-1 to bind to its binding sites; as a result SAF-1 wins and promotes VEGF expression. Some studies have shown that KLF4 represses VEGF expression through recruitment of histone deacetylases (HDACs) -2 and -3 at the VEGF promoter ${ }^{[101]}$. However this was not shown in MDA-MB-231 cancer cells but was experimentally proved in normal MCF-10A cells ${ }^{[101]}$. This suggests KLF4 with its tumor-suppressive role, inhibiting angiogenesis in mammary carcinoma leading to marked reduction in tumor size. Nevertheless sustained KLF4 expression in endothelial cells impaired tube formation and inhibited vascular network formation in implanted Matrigel plugs in nude mice ${ }^{[102]}$. Recent studies have thrown light on the role of KLF4 in epithelial to mesenchymal transition (EMT). Cancer cells undergo EMT transition that enables them to acquire the properties of migration and invasion. EMT provides cancer cells the ability to metastasize to distant sites. It represents series of events characterized by loss of epithelial characteristics such as cell polarity and cellular adhesion and gain of mesenchymal features with migratory and invasive properties, allowing metastatic spread to remote sites, turning into more malignant and aggressive phenotype ${ }^{[103]}$. EMT has been reported in various human cancers including breast cancer ${ }^{[104]}$, prostate cancer ${ }^{[105]}$, diffuse gastric carcinoma ${ }^{[106]}$, lung cancer ${ }^{[107]}$ and other epithelial cancer ${ }^{[108]}$. E-cadherin, N-cadherin, vimentin and $\beta$-catenin are essential EMT genes and alterations in their expression affect cell adhesion contacts, increases cell motility and facilitate migration of cells to distant sites, events that are critical in tumor progression. Loss of E-cadherin has been reported in poorly differentiated tumors and in highly invasive tumor cell lines. N-cadherin 
expression has been shown to be up-regulated in many tumors since its increased expression is directly correlated with cell mobility ${ }^{[109]}$. Transcription factors like Snail1/2, Slug, Zeb1/2, Twist and FoxC2 repress cell-cell interaction proteins such as E-cadherin, clauddin, occludins and ZO-family genes ${ }^{[110,111]}$. KLF4 inhibits EMT through its ability to activate E-cadherin and suppress Snail1 expression ${ }^{[112]}$. KLF4 negatively regulates EMT of GI and breast cancers ${ }^{[113,114]}$. Loss of KLF4 expression during EMT correlated with tumor angiogenesis, metastasis and aggressiveness ${ }^{[100]}$. Moreover in vitro and in vivo functional analyses shed light on the role played by KLF4 as a suppressor of HCC cell migration, invasion and metastasis ${ }^{[115]}$. Enforced KLF4 expression led to increase of E-cadherin mRNA levels and loss of mesenchymal markers $\mathrm{N}$-cadherin and vimentin in several HCC cell lines ${ }^{[115]}$. Consistent findings were reported in highly spreading "MDA-MB-231" breast cancer cell line where forced expression of KLF4 restores E-cadherin expression and suppresses migration and invasion ${ }^{[112]}$. This may suggest that KLF4 diminishes tumor development, inhibits exodus and invasion of cancer cells and suppresses metastasis in multiple carcinomas through its ability to inhibit EMT. KLF4 supports tumor suppressive properties by inhibiting colony formation, migration, and invasion of tumor cells. It has been shown to inhibit metastasis in several cancers, including esophageal ${ }^{[116]}$, pancreatic ${ }^{[49]}$ and colorectal cancer cells ${ }^{[67]}$. When KLF4 expression is reintroduced in MKN-45 gastric cancer cells it leads to appreciable reduction in proliferation, colony formation, preventing the metastasis in vitro and tumor formation in vivo ${ }^{[19]}$. KLF4 overexpression in RKO colon reduces tumorigenecity in vivo ${ }^{[67]}$. Overexpressed KLF4 resulted in reduction of renal cancer cell migration and inhibited metastasis ${ }^{[117]}$. KLF4 overexpression in PC-3 cells reduced cell migration and cell invasion by approximately $44 \%$ and $65 \%$ respectively in KLF4-infected (pMXshKLF4) cell population as compared to empty vector control ${ }^{[18]}$. Forced expression of KLF4 in metastatic MDA-MB-231 breast cancer cells inhibited both cell migration and invasion ${ }^{[112]}$. Consistent with the above observations, KLF4 overexpression in highly metastatic 4T1 cells significantly reduced both cell migration and invasion as compared to control ${ }^{[18]}$. Transient adenoviral expression of KLF4 (AdKLF4) in the 4T1 orthotropic mammary cancer model drastically reduced primary tumor growth and also micrometastases to lungs and liver as compared to control mice. On examination of lungs and liver from control and AdKLF4 tumor-bearing mice at 21 days after injection revealed that $60 \%$ of mice in the control group developed lung micrometastasis as compared to $10 \%$ in the AdKLF4 group, and liver micrometastases was reduced by $40 \%$ in the AdKLF4 group as compared to control ${ }^{[18]}$. In an orthotopic animal model of pancreatic ${ }^{[49]}$, gastric ${ }^{[19]}$ and colorectal cancers ${ }^{[119]}$, ectopic overexpression of KLF4 significantly suppressed tumor growth and metastasis in vivo. Moreover, tetracycline-inducible appearance of KLF4 in B cell progenitors of transgenic mice blocks transformation by BCR-ABL and depletes leukemic pre-B cells in vivo ${ }^{[51]}$.

KLF4 also exhibits oncogenic properties with its increased expression strongly associates with tumor formation in various cancer types. Numerous studies have shed light on the critical role played by KLF4 in development and progression of tumors. KLF4 mRNA and protein levels were up-regulated in $70 \%$ of breast cancer cases. The increased nuclear expression of KLF4 strongly correlates with the aggressiveness of breast cancer phenotypes ${ }^{[120,121]}$. High levels of KLF4 in breast cancer cells promote massive cell proliferation by stimulating increased resistance to apoptosis and uphold increased glycolytic phenotype ${ }^{[122]}$. Increased KLF4 expression in breast cancer cells activates platelet isoform of phosphofructokinase (PFKP) expression contributing to a stimulation of glycolytic metabolism. The elevated KLF4 levels in breast cancer cells enhance glucose uptake and lactate production by activating PFKP expression. PFKP, phosphofructokinase, liver (PFKL), phosphofructokinase, muscle (PFKM) are three most prominent isotypes of phosphofructokinase (PFK-1). Citrate and ATP have an inhibitory effect on PFKM whereas PFKL and PFKP isotypes are less sensitive to citrate and ATP and more sensitive to fructose 2,6-bisphosphate. Increased KLF4 expression induces PFKP by directly binding to its promoter region contributes to high glucose utilization supporting cell proliferation, growth and meeting other energy demands in breast cancer cells. KLF4 knockdown from breast cancer cells significantly decreased glucose uptake and lactate production by suppression of PFKP expression ${ }^{[122]}$. Over expressed KLF4 is directly linked with squamous cell carcinoma in larynx and skin ${ }^{[123,124]}$. Furthermore, dysplastic lesions resembling squamous cell carcinoma were observed in transgenic mice in which KLF4 has been ectopically expressed in basal keratinocytes ${ }^{[125]}$. Moreover, expression of KLF4 in cultured RK3E epithelial cells showed powerful transformation activity. KLF4 transformed RK3E cells can lead to tumors in xenografted mice ${ }^{[124]}$. The ability of KLF4 to function either as a controlling factor for cells that are proliferating are bearing offspring or a transmuting gene mainly depends on functional status of p21. 
p21 loss is sufficient to turn KLF4 from an inhibitor of proliferation into a transforming oncogene in vitro ${ }^{\text {[75]. }}$. 21 inactivation enables KLF4 to act as a tumor promoter by subduing p53. Thus we can safely say that KLF4 is part of the ever increasing list of genes that have dual context driven role in cancer.

\section{Concluding remarks}

Mounting evidence has established that KLF4 function is affected by its epigenetic context and it has the capacity to act as a transcriptional activator, repressor, tumor suppressor and an oncogene depending on the context. However, the exact molecular mechanisms by which KLF4 play multiple roles remain less understood. The studies provided ample evidence to support tumor suppressive role of KLF4 and how its loss of expression affects the genes critical in tumor formation and survival contributing to unbridled proliferation, sustained vascularization, tissue invasion and metastasis. KLF4 also exhibits oncogenic properties with its increased expression strongly associates with tumor formation in various cancer types. Given the role of KLF4 in various pathways central to tumor formation, detailed understanding of molecular mechanism of KLF4 functional role could help in identifying the therapeutic target that could mimic the action of KLF4 to combat neoplasm. Understanding of KLF4 interactome and its genomics will be of great importance in resolving as to how cell maintains an orchestrated balance between the genes coding for tumor suppressors and tumor promoters. This phenomenon will be crucial in developing various preventive/curative strategies for various types of oncogenic processes.

\section{References}

[1] McConnell BB, Yang VW. Mammalian Krüppel-Like Factors in Health and Diseases. Physiol Rev. 2010; 90: 1337-1381. http://dx.doi.org/10.1152/physrev.00058.2009

[2] Dang DT, Pevsner J, Yang VW. The biology of the mammalian Krüppel-like family of transcription factors. Int J Biochem Cell Biol. 2000; 32: 1103-1121. http://dx.doi.org/10.1016/S1357-2725(00)00059-5

[3] Chen Z, Lei T, Chen X, et al. Porcine KLF gene family: Structure, mapping, and phylogenetic analysis. Genomics. 2010; 95: 111-119. http://dx.doi.org/10.1016/j.ygeno.2009

[4] Pei J, Grishin NV. A new family of predicted krüppel-like factor genes and pseudogenes in placental mammals. PLoS One. 2013; 8: e81109. http://dx.doi.org/10.1371/journal.pone.0081109

[5] Shields JM, Christy RJ, Yang VW. Identification and characterization of a gene encoding a gut-enriched Krüppel-like factor expressed during growth arrest. J Biol Chem. 1996; 271: 20009-20017. http://dx.doi.org/10.1074/jbc.271.33.20009

[6] Garrett-Sinha LA, Eberspaecher H, Seldin MF, et al. Gene for a novel zinc-finger protein expressed in differentiated epithelial cells and transiently in certain mesenchymal cells. J Biol Chem. 1996; 271: 31384-31390. PMid:8940147 http://dx.doi.org/10.1074/jbc.271.49.31384

[7] Panigada M, Porcellini S, Sutti F, et al. GKLF in thymus epithelium as a developmentally regulated element of thymocytestroma. Mech Dev. 1999; 81: 103-113. http://dx.doi.org/10.1016/S0925-4773(98)00237-8

[8] Chiambaretta F, De Graeve F, Turet G, et al. Cell and tissue specific expression of human Kruppel-like transcription factors in human ocular surface. MolVis [Internet]. 2004; 10: 901-909. PMid:15570219. Available from: http://www.molvis.org/molvis/v10/a108/

[9] Cullingford TE, Butler MJ, Marshall AK, et al. Differential regulation of Krüppel-like factor family transcription factor expression in neonatal rat cardiac myocytes: effects of endothelin-1, oxidative stress and cytokines. Biochim Biophys Acta. 2008; 1783: 1229-1236. http://dx.doi.org/10.1016/j.bbamcr.2008.03.007

[10] Fruman DA, Ferl GZ, An SS, et al. Phosphoinositide 3-kinase and Bruton's tyrosine kinase regulate overlapping sets of genes in B lymphocytes. PNAS. 2002; 99: 359-364. http://dx.doi.org/10.1073/pnas.012605099

[11] Vangapandu H, Ai W. Kruppel like factor 4 (KLF4); a transcription factor with diverse context-dependent functions. Gene Ther Mol Biol. 2009; 13: 194-204.

[12] Retera JM, Leers MP, Sulzer MA, et al. The expression of beta-catenin in non-small-cell lung cancer: a clinicopathological study. J Clin Pathol. 1998; 51: 891-894. http://dx.doi.org/10.1136/jcp.51.12.891

[13] Ebert MPA, Fei G, Kahmann S, et al. Increased $\beta$-catenin mRNA levels and mutational alterations of the APC and $\beta$-catenin gene are present in intestinal-type gastric cancer. Carcinogenesis. 2002; 23: 87-91. http://dx.doi.org/10.1093/carcin/23.1.87 
[14] Lin SY, Xia W, Wang, JC, et al. Beta-catenin, a novel prognostic marker for breast cancer: its roles in cyclin D1 expression and cancer progression. Proc Natl Acad Sci USA. 2000; 97: 4262-4266. http://dx.doi.org/10.1073/pnas.060025397

[15] Evans PM, Chen X, Zhang W, et al. KLF4 interacts with beta-catenin/TCF4 and blocks p300/CBP recruitment by beta-catenin. Mol Cell Biol. 2010; 30: 372-381. http://dx.doi.org/10.1128/MCB.00063-09

[16] Zhang W, Chen X, Kato Y, et al. Novel cross talk of Kruppel-like factor 4 and beta-catenin regulates normal intestinal homeostasis and tumor repression. Mol Cell Biol. 2006; 26: 2055-2064. http://dx.doi.org/10.1128/MCB.26.6.2055-2064.2006

[17] Sellak H, Wu S, Lincoln TM. Sox 9 and KLF4 transcription factors antagonize $\beta$-catenin and inhibit TCF-activity in cancer cells. Biochim Biophys Acta. 2012; 1823: 1666-75. http://dx.doi.org/10.1016/j.bbamcr.2012.06.027

[18] Wang Z, Li Y, Sarkar FH. Notch Signaling Proteins: Legitimate Targets for Cancer Therapy. Curr Protein Pept Sci. 2010; 11: 398-408. http://dx.doi.org/10.2174/138920310791824039

[19] Zhang N, Zhang J, Shuai L, et al. Krüppel-like factor 4 negatively regulates $\beta$-catenin expression and inhibits the proliferation, invasion and metastasis of gastric cancer. Int J Oncol. 2012; 40: 2038-2048. http://dx.doi.org/10.3892/ijo.2012.1395

[20] Chan SM, Weng AP, Tibshirani R, et al. Notch signals positively regulate activity of the mTOR pathway in T-cell acute lymphoblastic leukemia. Blood. 2007; 110: 278-286. http://dx.doi.org/10.1182/blood-2006-08-039883

[21] Ghaleb AM, Aggarwal G, Bialkowska AB, et al. Notch inhibits expression of the Krüppel-like factor 4 tumor suppressor in the intestinal epithelium. Mol Cancer Res. 2008; 6: 1920-1927. http://dx.doi.org/10.1158/1541-7786.MCR-08-0224

[22] Zheng H, Pritchard DM, Yang X, et al. KLF4 gene expression is inhibited by the notch signaling pathway that controls goblet cell differentiation in mouse gastrointestinal tract. Am J Physiol Gastrointest Liver Physiol. 2009; 296: G490-8. http://dx.doi.org/10.1152/ajpgi.90393.2008

[23] Lambertini C, Pantano S, Dotto GP. Differential control of Notch1 gene transcription by Klf4 and Sp3 transcription factors in normal versus cancer-derived keratinocytes. PLoS One. 2010; 5: e10369. http://dx.doi.org/10.1371/journal.pone.0010369

[24] Hale AT, Tian H, Anih E, et al. Endothelial Kruppel-like factor 4 regulates angiogenesis and the Notch signaling pathway. J Biol Chem. 2014; 289: 12016-12028. http://dx.doi.org/10.1074/jbc.M113.530956

[25] Carthew RW, Sontheimer EJ. Origins and mechanisms of miRNAs and siRNAs. Cell. 2009; 136: $642-655$. http://dx.doi.org/10.1016/j.cell.2009.01.035

[26] Wahid F, Shehzad A, Khan T, et al. MicroRNAs: synthesis, mechanism, function, and recent clinical trials Biochim Biophys Acta. 2010; 1803: 1231-1243. http://dx.doi.org/10.1016/j.bbamcr.2010.06.013

[27] Ambros V. The functions of animal microRNAs. Nature. 2004; 431: 350-355. PMid:15372042. http://dx.doi.org/10.1038/nature02871

[28] Calin GA, Dumitru CD, Shimizu M, et al. Frequent deletions and down-regulation of micro-RNA genes miR15 and miR16 at $13 q 14$ in chronic lymphocytic leukemia. Proc Natl Acad Sci USA. 2002; 99: 15524-15529.

http://dx.doi.org/10.1073/pnas.242606799

[29] Garzon R, Volinia S, Liu CG, et al. MicroRNA signatures associated with cytogenetics and prognosis in acute myeloid leukema. Blood. 2008; 111: 3183-3189. http://dx.doi.org/10.1182/blood-2007-07-098749

[30] de Oliveira JC, Scrideli CA, Brassesco MS, et al. Differential miRNA expression in childhood acute lymphoblastic leukemia and association with clinical and biological features. Leuk Res. 2012; 36: 293-298. http://dx.doi.org/10.1016/j.leukres.2011.10.005

[31] Kluiver J, Poppema S, de Jong D, et al. BIC and miR-155 are highly expressed in Hodgkin, primary mediastinal and diffuse large B cell lymphomas. J Pathol. 2005; 207: 243-249. http://dx.doi.org/10.1002/path.1825

[32] Tang W, Zhu Y, Gao J, et al. MicroRNA-29a promotes colorectal cancer metastasis by regulating matrix metalloproteinase 2 and E-cadherin via KLF4. Br J Cancer. 2013; 21: 450-458. http://dx.doi.org/10.1038/bjc.2013.724

[33] Sun S, Zheng B, Han M, et al. miR-146a and Kruppel-like factor 4 form a feedback loop to participate in vascular smooth muscle cell proliferation. EMBO Rep. 2011; 12: 56-62. http://dx.doi.org/10.1038/embor.2010.172

[34] Kaul D, Hussain A. Cellular AATF gene encodes a novel miRNA that can contribute to HIV-1 latency. Indian J Biochem Biophys. 2009; 46: 237-240.

[35] Kaul D, Sasikala M, Raina A. Regulatory role of miR-2909 in cell-mediated immune response. Cell Biochem Funct. 2012; 30: 500-504. http://dx.doi.org/10.1002/cbf.2828

[36] Sharma M, Sharma S, Arora M, et al. Regulation of cellular CCND1 gene by arsenic is mediated through miR-2909. Gene. 2013; 522: 60-64. http://dx.doi.org/10.1016/j.gene.2013.03.058

[37] Malik D, Kaul D, Chauhan N, et al. miR-2909-mediated regulation of KLF4: a novel molecular mechanism for differentiating between B-cell and T-cell pediatric acute lymphoblastic leukemias. Molecular Cancer. 2014; 13: 175.

http://dx.doi.org/10.1186/1476-4598-13-175

[38] Arora M, Kaul D, Sharma YP. Human coronary heart disease: importance of blood cellular miR-2909 RNomics. Mol Cell Biochem. 1982; 46: 49-63. http://dx.doi.org/10.1007/s11010-014-2017-3 
[39] Xu N, Papagiannakopoulos T, Pan G, et al. MicroRNA-145 regulates OCT4, SOX2 and KLF4 and represses pluripotency in human embryonic stem cells. Cell. 2009; 137: 647-658. http://dx.doi.org/10.1016/j.cell.2009.02.038

[40] Tian Y, Luo A, Cai Y, et al. MicroRNA-10b promotes migration and invasion through KLF4 in human esophageal cancer cell lines. J Biol Chem. 2010; 285: 7986-7994. http://dx.doi.org/10.1074/jbc.M109.062877

[41] Lutherborrow M, Bryant A, Jayaswal V, et al. Expression profiling of cytogenetically normal acute myeloid leukemia identifies MicroRNAs that target genes involved in monocytic differentiation. Am J Hematol. 2011; 86: 2-11. http://dx.doi.org/10.1002/ajh.21864

[42] Zhang W, Geiman D, Shields JM, et al. The gut-enriched Kruppel-like factor (Kruppel-like factor 4) mediates the transactivating effect of p53 on the p21WAF1/Cip1 promoter. J Biol Chem. 2000; 275: 18391-18398. http://dx.doi.org/10.1074/jbc.C000062200

[43] Chen X, Johns DC, Geiman DE, et al. Krüppel-like Factor 4 (Gut-enriched Krüppel-like Factor) Inhibits Cell Proliferation by Blocking G1/S Progression of the Cell Cycle Biol Chem. 2001; 276: 30423-30428. http://dx.doi.org/10.1074/jbc.M101194200

[44] Nickenig G, Baudler S, Muller C, et al. Redox-sensitive vascular smooth muscle cell proliferation is mediated by GKLF and Id3 in vitro and in vivo. Faseb J. 2002; 16: 1077-1086. http://dx.doi.org/10.1096/fj.01-0570com

[45] Yoon HS, Chen X, Yang VW. Krüppel-like factor 4 mediates p53-dependent G1/S cell cycle arrest in response to DNA damage. J Biol Chem. 2003; 278: 2101-2105. http://dx.doi.org/10.1074/jbc.M211027200

[46] Yoon HS, Yang VW. Requirement of Krüppel-like factor 4 in preventing entry into mitosis following DNA damage. J Biol Chem. 2004; 279: 5035-5041. http://dx.doi.org/10.1074/jbc.M307631200

[47] Chen ZY, Shie JL, Tseng CC. Gut-enriched Krüppel-like factor represses ornithine decarboxylase gene expression and functions as checkpoint regulator in colonic cancer cells. J Biol Chem. 2002; 277: 46831-46839. http://dx.doi.org/10.1074/jbc.M204816200

[48] $\mathrm{Hu}$ W, Hofstetter WL, Li H, et al. Putative tumor-suppressive function of Kruppel-like factor 4 in primary lung carcinoma. Clin Cancer Res. 2009; 15: 5688-5695. http://dx.doi.org/10.1158/1078-0432.CCR-09-0310

[49] Wei D, Kanai M, Jia Z, et al. Krüppel-like Factor 4 Induces p27Kip1 Expression in and Suppresses the Growth and Metastasis of Human Pancreatic Cancer Cells. Cancer Res. 2008; 68: 4631-4639. http://dx.doi.org/10.1158/0008-5472.CAN-07-5953

[50] Zhao W, Hisamuddin IM, Nandan MO, et al. Identification of Kruppel-like factor 4 as a potential tumor suppressor gene in colorectal cancer. Oncogene. 2004; 23: 395-402. http://dx.doi.org/10.1038/sj.onc.1207067

[51] Kharas MG, Yusuf I, Scarfone VM, et al. KLF4 suppresses transformation of pre-B cells by ABL oncogenes. Blood. 2007 Jan; 109(2): 747-755. http://dx.doi.org/10.1182/blood-2006-03-011106

[52] Zhang W, Shields JM, Sogawa K, et al. The gut-enriched Krüppel-like factor suppresses the activity of the CYP1A1 promoter in an Sp1-dependent fashion. J Biol Chem. 1998; 273: 17917-17925. http://dx.doi.org/10.1074/jbc.273.28.17917

[53] Miller KA, Eklund EA, Peddinghaus ML, et al. Krüppel-like factor 4 regulates laminin alpha 3A expression in mammary epithelial cells. J Biol Chem. 2001; 276: 42863-42868. http://dx.doi.org/10.1074/jbc.M108130200

[54] Brembeck FH, Rustgi AK. The tissue-dependent keratin 19 gene transcription is regulated by GKLF/KLF4 and Sp1. J Biol Chem. 2000; 275: 28230-28239. http://dx.doi.org/10.1074/jbc.M004013200

[55] Okano J, Opitz OG, Nakagawa H, et al. The Krüppel-like transcriptional factors Zf9 and GKLF coactivate the human keratin 4 promoter and physically interact. FEBS Letters. 2000; 473: 95-100. http://dx.doi.org/10.1016/S0014-5793(00)01468-X

[56] Katz JP, Perreault N, Goldstein BG, et al. The zinc-finger transcription factor Klf4 is required for terminal differentiation of goblet cells in the colon. Dev. 2002; 129: 2619-2628.

[57] Segre JA, Bauer C, Fuchs E. Klf4 is a transcription factor required for establishing the barrier function of the skin. Nat Genet. 1999; 22: 356-360. http://dx.doi.org/10.1038/11926

[58] Mahatan CS, Kaestner KH, Geiman DE, et al. Characterization of the structure and regulation of the murine gene encding gut-enriched Krüppel-like factor (Krüppel-like factor 4). Nucleic Acids Res. 1999; 27: 4562-4569. http://dx.doi.org/10.1093/nar/27.23.4562

[59] Fang R, Santiago NA, Olds LC, et al. The homeodomain protein Cdx2 regulates lactase gene promoter activity during enterocyte differentiation. Gastroenterology. 2000; 118: 115-127. http://dx.doi.org/10.1016/S0016-5085(00)70420-3

[60] Feinberg MW, Wara AK, Cao Z, et al. The Kruppel like factor KLF4 is a critical regulator of monocyte differentiation. EMBO J. 2007; 26: 4138-4148. http://dx.doi.org/10.1038/sj.emboj.7601824

[61] Dong H, Deng M, Song M, et al. Kruppel-like factor 4 promotes differentiation of endothelial progenitor cells into endothelial cells by up-regulating endothelial nitric oxide synthase. Heart. 2011; 97: A52. http://dx.doi.org/10.1136/heartjnl-2011-300867.152

[62] Lin H, Xu L, Liu H, et al. KLF4 promotes the odontoblastic differentiation of human dental pulp cells. J Endod. 2011; 37: 948-954. http://dx.doi.org/10.1016/j.joen.2011.03.030 
[63] Swamynathan SK, Katz JP, Kaestner KH, et al. Conditional Deletion of the Mouse KLF4 Gene Results in Corneal Epithelial Fragility, Stromal Edema, and Loss of Conjunctival Goblet Cells. Mol Cell Biol. 2007; 27: 1182-194. http://dx.doi.org/10.1128/MCB.00846-06

[64] Birsoy K, Chen Z, Friedman J. Transcriptional regulation of adipogenesis by KLF4. Cell Metab. 2008; 7: $339-347$. http://dx.doi.org/10.1016/j.cmet.2008.02.001

[65] Wei D, Kanai M, Huang S, et al. Emerging role of KLF4 in human gastrointestinal cancer. Carcinogenesis. 2006 ; 27 : 23-31. http://dx.doi.org/10.1093/carcin/bgi243

[66] Ohnishi S, Ohnami S, Laub F, et al. Down-regulation and growth inhibitory effect of epithelial-type Kruppel-like transcription factor KLF4, but not KLF5, in bladder cancer. Biochem Biophys Res Commun. 2003; 308: 251-256. http://dx.doi.org/10.1016/S0006-291X(03)01356-1

[67] Dang DT, Chen X, Feng J, et al. Overexpression of Kruppel-like factor 4 in the human colon cancer cell line RKO leads to reduced tumorigenecity. Oncogen. 2003; 22: 3424-3430. http://dx.doi.org/10.1038/sj.onc.1206413

[68] Li Z, Zhao J, Li Q, et al. KLF4 promotes hydrogen-peroxide-induced apoptosis of chronic myeloid leukemia cells involving the bcl-2/bax pathway. Cell Stress Chaperones. 2010; 15: 905-912. http://dx.doi.org/10.1007/s12192-010-0199-5

[69] Liu MD, Liu Y, Liu JW, et al. Effect of Kruppel-like factor 4 overexpression on heat stress-induced apoptosis of Raw264.7 macrophages. Zhong Nan Da XueXueBao Yi Xue Ban. 2007; 32(6): 1002-1006. PMid:18182717.

[70] Liu MD, Liu Y, Liu JW, et al. Effect of Kruppel-like factor 4 overexpression on heat stress-induced apoptosis of C2C12 cells. Chin J Arterioscler. 2008; 16: 265-267.

[71] Wang Ji, Place RF, HuangV, et al. Prognostic Value and Function of KLF4 in Prostate Cancer: RNAa and Vector-Mediated Overexpression Identify KLF4 as an Inhibitor of Tumor Cell Growth and Migration. Cancer Res. 2010; 70 : $10182-91$. http://dx.doi.org/10.1158/0008-5472.CAN-10-2414

[72] Yasunaga J, Taniguchi Y, Nosaka K, et al. Identification of aberrantly methylated genes in association with adult T-cell leukemia. Cancer Res. 2004; 64: 6002-6009. http://dx.doi.org/10.1158/0008-5472.CAN-04-1422

[73] Rowland BD, Bernards R, Peeper DS. The KLF4 tumour suppressor is a transcriptional repressor of p53 that acts as a context-dependent oncogene. Nat Cell Biol. 2005; 7: 1074-1082. http://dx.doi.org/10.1038/ncb1314

[74] Yang Y, Goldstein BG, Chao HH, et al. KLF4 and KLF5 regulate proliferation, apoptosis and invasion in esophageal cancer cells. Cancer Biol Ther. 2005; 4: 1216-1221. http://dx.doi.org/10.4161/cbt.4.11.2090

[75] Rowland BD, Peeper DS. KLF4, p21 and context-dependent opposing forces in cancer. Nat Rev Cancer. 2006; 611: 857-866. http://dx.doi.org/10.1038/nrc1780

[76] Patel M, Yang S. Advances in reprogramming somatic cells to induced pluripotent stem cells. Stem Cell Rev. 2010 ; 6: 367-380. http://dx.doi.org/10.1007/s12015-010-9123-8

[77] Stadtfeld M, Hochedlinger K. Induced pluripotency: history, mechanisms, and applications. Genes Dev. 2010; 24 : $2239-2263$. http://dx.doi.org/10.1101/gad.1963910

[78] Nakagawa M, Koyanagi M, Tanabe K, et al. Generation of induced pluripotent stem cells without Myc from mouse and human fibroblasts. Nat Biotechnol. 2008; 26: 101-106. http://dx.doi.org/10.1038/nbt1374

[79] Boiani M, Eckardt S, Scholer HR, et al. Oct4 distribution and level in mouse clones: consequences for pluripotency. Genes Dev. 2002; 16: 1209-1219. http://dx.doi.org/10.1101/gad.966002

[80] Kim JB, Zaehres H, Wu G, et al. Pluripotent stem cells induced from adult neural stem cells by reprogramming with two factors. Nature. 2008; 454: 646-650. http://dx.doi.org/10.1038/nature07061

[81] Zhang P, Andrianakos R, Yang Y, et al. Kruppel-like factor 4 (Klf4) prevents embryonic stem (ES) cell differentiation by regulating Nanog gene expression. J Biol Chem. 2010; 285: 9180-9189. http://dx.doi.org/10.1074/jbc.M109.077958

[82] Guo G, Yang J, Nichols J, et al. KLF4 reverts developmentally programmed restriction of ground state pluripotency. Dev. 2009; 136: 1063-1069. http://dx.doi.org/10.1242/dev.030957

[83] Zammarchi F, Morelli M, Menicagli M, et al. KLF4 is a novel candidate tumor suppressor gene in pancreatic ductal carcinoma. Am J Pathol. 2011; 178: 361-372. http://dx.doi.org/10.1016/j.ajpath.2010.11.021

[84] Nakahara Y, Northcott PA, Li M, et al. Genetic and epigenetic inactivation of Kruppel-like factor 4 in medulloblastoma. Neoplasia. 2010; 12: 20-27. PMid:20072650.

[85] Yang WT, Zheng PS. Promoter Hypermethylation of KLF4 Inactivates Its Tumor Suppressor Function in Cervical Carcinogenesis. PLoS ONE. 2014; 9: e88827. http://dx.doi.org/10.1371/journal.pone.0088827

[86] Guan H, Xie L, Leithäuser F, et al. KLF4 is a tumor suppressor in B-cell non-Hodgkin lymphoma and in classic Hodgkin lymphoma. Blood. 2010; 116: 1469-1478. http://dx.doi.org/10.1182/blood-2009-12-256446 
[87] Good KL, Tangye SG. Decreased expression of Kruppel-like factors in memory B cells induces the rapid response typical of secondary antibody responses. Proc. Natl. Acad. Sci. USA. 2007; 104: 13420-13425. http://dx.doi.org/10.1073/pnas.0703872104

[88] Yusuf I, Kharas MG, Chen J, et al. KLF4 is a FOXO target gene that suppresses B cell proliferation. Int Immunol. 2008; 20: 671-681. http://dx.doi.org/10.1093/intimm/dxn024

[89] Dang DT, Bachman KE, Mahatan CS, et al. Decreased expression of the gut-enriched Krüppel-like factor gene in intestinal adenomas of multiple intestinal neoplasia mice and in colonic adenomas of familial adenomatous polyposis patients. FEBS Lett. 2000; 476: 203-207. http://dx.doi.org/10.1016/S0014-5793(00)01727-0

[90] Kanai M, Wei D, Li Q, et al. Loss of Kruppel-like factor expression contributes to SP1 over expression and human gastric cancer development and progression. Clin Cancer Res. 2006; 12: 6395-6402. http://dx.doi.org/10.1158/1078-0432.CCR-06-1034

[91] Yao JC, Wang L, Wei D, et al. Association between Expression of Transcription Factor Sp1 and Increased Vascular Endothelial Growth Factor Expression, Advanced Stage, and Poor Survival in Patients with Resected Gastric Cancer. Clin Cancer Res. 2004 June; 10: 4109-4117. http://dx.doi.org/10.1158/1078-0432.CCR-03-0628

[92] Wei D, Wang L, He Y, et al. Celecoxib inhibits vascular endothelial growth factor expression in and reduces angiogenesis and metastasis of human pancreatic cancer via suppression of Sp1 transcription factor activity. Cancer Res. 2004; 64: 2030. http://dx.doi.org/10.1158/0008-5472.CAN-03-1945

[93] Jutooru I, Chadalapaka G, Safe S. Critical analysis of the potential for the therapeutic targeting of the Sp1 transcription factor in pancreatic cancer. Gastrointestinal Cancer: Targets and Therapy. 2014; 4: 65-74. http://dx.doi.org/10.2147/GICTT.S48992

[94] Hsu TI, Wang MC, Chen SY, et al. Sp1 expression regulates lung tumor progression. Oncogene. 2012; 31 : $3973-3988$. http://dx.doi.org/10.1038/onc.2011.568

[95] Kumar AP, Butler AP. Enhanced Sp1 DNA-binding activity in murine keratinocyte cell lines and epidermal tumors. Cancer Lett. 1999; 137: 159-65. http://dx.doi.org/10.1016/S0304-3835(98)00351-6

[96] Hosoi Y, Watanabe T, Nakagawa K, et al. Up-regulation of DNA-dependent protein kinase activity and Sp1 in colorectal cancer. Int J Oncol. 2004; 25: 461-468. http://dx.doi.org/10.3892/ijo.25.2.461

[97] Higgins KJ, Abdelrahim M, Liu S, et al. Regulation of vascular endothelial growth factor receptor-2 expression in pancreatic cancer cells by Sp proteins. Biochem Biophys Res Commun. 2006; 345: 292-301. http://dx.doi.org/10.1016/j.bbrc.2006.04.111

[98] Yuan P, Wang L, We D, et al. Therapeutic inhibition of Sp1 expression in growing tumors by mithramycin a correlates directly with potent antiangiogenic effects on human pancreatic cancer. Cancer. 2007; 110: 2682-2690. http://dx.doi.org/10.1002/cncr.23092

[99] Kaul D, Mehrotra A. Functional characterization of AATF transcriptome in human leukemic cells. Mol Cell Biochem. 2007; 297: 215-220. http://dx.doi.org/10.1007/s11010-006-9317-1

[100] Tiwari N, Meyer-Schaller N, Arnold P, et al. Klf4 Is a Transcriptional Regulator of Genes Critical for EMT, Including Jnk1 (Mapk8). PLoS ONE. 2013; 8: e57329. http://dx.doi.org/10.1371/journal.pone.0057329

[101] Ray A, Alalem M, Ray BK. Loss of Epigenetic Kruppel-like Factor 4 Histone Deacetylase (KLF-4-HDAC)-mediated Transcriptional Suppression Is Crucial in Increasing Vascular Endothelial Growth Factor (VEGF) Expression in Breast Cancer. J Biol Chem. 2013; 288: 27232-27242. http://dx.doi.org/10.1074/jbc.M113.481184

[102] Zheng X, Li A, Zhao L, et al. Key role of microRNA-15a in the KLF4 suppressions of proliferation and angiogenesis in endothelial and vascular smooth muscle cells. Biochem Biophys Res Commun. 2013; 437: 625-631. http://dx.doi.org/10.1016/j.bbrc.2013.07.017

[103] Lamouille S, Xu J, Derynck R. Molecular mechanisms of epithelial-mesenchymal transition. Nat Rev Mol Cell Biol. 2014; 15: 178-196. http://dx.doi.org/10.1038/nrm3758

[104] Wang Y, Zhou BP. Epithelial-mesenchymal transition in breast cancer progression and metastasis. Chin J Cancer. 2011; 30: 603-611. http://dx.doi.org/10.5732/cjc.011.10226

[105] Grant CM, Kyprianou N. Epithelial mesenchymal transition (EMT) in prostate growth and tumor progression. Transl Androl Urol. 2013; 2. http://dx.doi.org/10.3978/j.issn.2223-4683.2013.09.04

[106] Katoh M. Epithelial-mesenchymal transition in gastric cancer (Review). International Journal of Oncology. 2005; 27 : 1677-1683. http:dx.doi.org/10.3892/ijo.27.6.1677

[107] Xiao D, He J. Epithelial mesenchymal transition and lung cancer. J Thorac Dis. 2010; 2: 154-159. http://dx.doi.org/10.3978/j.issn.2072-1439.2010.02.03.7.

[108] Larue L, Bellacosa A. Epithelial-mesenchymal transition in development and cancer: role of phosphatidylinositol 3' kinase/AKT pathways. Oncogene. 2005; 24: 7443-7454. http://dx.doi.org/10.1038/sj.onc.1209091

[109] Margaret J, Wheelock MJ, Shintani Y, et al. Cadherin switching. J Cell Sci. 2008; 121: 727-735. http://dx.doi.org/10.1242/jcs.000455 
[110] Birchmeier W, Behrens J. Cadherin expression in carcinomas: role in the formation of cell junctions and the prevention of invasiveness. Biochim Biophys Acta. 1994; 1198: 11-26. http://dx.doi.org/10.1016/0304-419X(94)90003-5

[111] Grille SJ, Bellacosa A, Upson J, et al. The protein kinase Akt induces epithelial mesenchymal transition and promotes enhanced motility and invasiveness of squamous cell carcinoma lines. Cancer Res. 2003; 63: 2172-2178. PMid:12727836.

[112] Yori JL, Johnson E, Zhou G, et al. Krüppel-like Factor 4 Inhibits Epithelial-to-Mesenchymal Transition through Regulation of E-cadherin Gene Expression. J Biol Chem. 2010; 285: 16854-16863. http://dx.doi.org/10.1074/jbc.M110.114546

[113] Cui J, Shi M, Xie K. Regulation of EMT by KLF4 in Gastrointestinal Cancer. Curr Cancer Drug Targets. 2013; $13: 986-995$. http://dx.doi.org/10.2174/15680096113136660104

[114] Tetreault MP, Yang Y, Katz JP. Krüppel-like factors in cancer. Nature Reviews Cancer. 2013; 13: 701-713. http://dx.doi.org/10.1038/nrc3582

[115] Lin ZS, Chu HC, Yen YC, et al. Krüppel-Like Factor 4, a Tumor Suppressor in Hepatocellular Carcinoma Cells Reverts Epithelial Mesenchymal Transition by Suppressing Slug Expression. PLoS ONE. 2013; 8. http://dx.doi.org/10.1371/journal.pone.0043593

[116] Wei D, Gong W, Kanai M, et al. Drastic down-regulation of Kruppel-like factor 4 expression is critical in human gastric cancer development and progression. Cancer Res. 2005; 65: 2746-2754. http://dx.doi.org/10.1158/0008-5472.CAN-04-3619

[117] Heng Li, Wang Ji, Xiao W, et al. Epigenetic alterations of Krüppel-like factor 4 and its tumor suppressor function in renal cell carcinoma. Carcinogenesis. 2013 May; 34(10): 2262-2270. PMid:23722653. http://dx.doi.org/10.1093/carcin/bgt189

[118] Yori JL, Seachrist DD, Johnson E, et al. Krüppel-like Factor 4 Inhibits Tumorigenic Progression and Metastasis in a Mouse Model of Breast Cancer. Neoplasia. 2011; 13: 601-610. PMid:21750654.

[119] Chen HY, Lin YM, Chung HC, et al. miR-103/107 promote metastasis of colorectal cancer by targeting the metastasis suppressors DAPK and KLF4. Cancer Res. 2012; 72: 3631-3641. http://dx.doi.org/10.1158/0008-5472.CAN-12-0667

[120] Pandya AY, Talley LI, Frost AR, et al. Nuclear localization of KLF4 is associated with an aggressive phenotype in early-stage breast cancer. Clin Cancer Res. 2004; 10: 2709-2719. http://dx.doi.org/10.1158/1078-0432.CCR-03-0484

[121] Foster KW, Frost AR, McKie-Bell P, et al. Increase of GKLF messenger RNA and protein expression during progression of breast cancer. Cancer Res. 2000 Nov; 60(22): 6488-6495. PMid:11103818.

[122] Moon JS, Kim HE, Koh E, et al. Krüppel-like factor 4 (KLF4) activates the transcription of the gene for the platelet isoform of phosphofructokinase (PFKP) in breast cancer. J Biol Chem.2011; 286: 23808-23816. http://dx.doi.org/10.1074/jbc.M111.236737

[123] Huang CC, Liu Z, Li X, et al. KLF4 and PCNA identify stages of tumor initiation in a conditional model of cutaneous squamous epithelial neoplasia. Cancer Biol Ther. 2005; 4: 1401-1408. http://dx.doi.org/10.4161/cbt.4.12.2355

[124] Foster KW, Ren S, Louro ID, et al. Oncogene expression cloning by retroviral transduction of adenovirus E1A-immortalized rat kidney RK3E cells: transformation of a host with epithelial features by c-Myc and the zinc finger protein GKLF. Cell Growth \& Differ. 1999; 10: 423-434. PMid:10392904.

[125] Foster KW, Liu Z, Nail CD, et al. Induction of KLF4 in basal keratinocytes blocks the proliferation-differentiation switch and initiates squamous epithelial dysplasia. Oncogene. 2000; 24: 1491-1500. http://dx.doi.org/10.1038/sj.onc.1208307 